\title{
Combining Inverted Echo Sounder and Horizontal Electric Field Recorder Measurements to Obtain Absolute Velocity Profiles
}

\author{
Christopher S. Meinen And Douglas S. Luther \\ University of Hawaii at Manoa, Honolulu, Hawaii \\ D. Randolph Watts And Karen L. Tracey \\ University of Rhode Island, Narranganset, Rhode Island \\ Alan D. Chave \\ Woods Hole Oceanographic Institution, Woods Hole, Massachusetts \\ JAMES RICHMAN \\ Oregon State University, Corvallis, Orgegon
}

(Manuscript received 22 June 2001, in final form 15 March 2002)

\section{ABSTRACT}

\begin{abstract}
Profiles of absolute velocity are difficult to obtain in the ocean, especially over long periods of time at the same location. This paper presents a method of estimating full water column absolute horizontal velocity profiles as a function of time by combining historical hydrography with the measurements from two separate instruments, the inverted echo sounder (IES) and the horizontal electric field recorder (HEFR). Hydrography is used to construct temperature, salinity, and specific volume anomaly characteristics as functions of the independent variables pressure and seafloor-to-sea-surface round-trip acoustic travel time $(\tau)$. Each IES measured $\tau$ is combined with these two-dimensional characteristics to estimate the profile of specific volume anomaly, which then is integrated vertically to obtain profiles of geopotential height anomaly $(\Delta \phi)$. Profiles of $\Delta \phi$ from adjacent IES sites are differenced to yield vertical profiles of relative geostrophic velocity. Horizontal electric fields arising from the vertically averaged horizontal water velocity provide the requisite referencing of the IES-derived relative velocities. Comparisons are presented between HEFR + IES absolute velocities in the Southern Ocean near $51^{\circ} \mathrm{S}$, $143.5^{\circ} \mathrm{E}$ and absolute velocities determined via hydrography, acoustic Doppler current profiler, and current meter.
\end{abstract}

\section{Introduction}

Absolute velocity profiles in the ocean are difficult to obtain particularly as time series measurements. All of the direct measuring instruments, such as mechanical current meters and acoustic Doppler current profilers (ADCPs), have significant limitations. Mechanical current meters measure velocities at a single point, so that acquiring top-to-bottom velocity profiles with good vertical resolution is essentially prohibited by the cost of large numbers of instruments. ADCPs provide significantly more information than a mechanical current meter, but their vertical range is limited to under $600 \mathrm{~m}$,

Corresponding author address: Dr. Christopher S. Meinen, Department of Oceanography, University of Hawaii at Manoa, 1000 Pope Road, MSB 205, Honolulu, HI 96822.

E-mail: cmeinen@soest.hawaii.edu decreasing with depth due to decreasing concentrations of acoustic scatterers, although the range is likely to increase to $1000 \mathrm{~m}$ in the near future for ideal conditions. Moored profilers that can provide near-full water column absolute velocity profiles are currently under development; however, taking hourly measurements over a 1-2-yr deployment is beyond the capability of the presently available instruments (Doherty et al. 1999). Furthermore, moored velocity profilers will have difficulty in obtaining measurements in the upper water column due to mooring motion, and survivability will be a problem when deployed near the surface in regions of high surface wave action, fishing activity, and/or vandalism as is true for any current meter mooring. Lagrangian floats, such as the RAFOS or (profiling) autonomous Lagrangian circulation explorer [(P)ALACE] floats, measure absolute velocities along flow pathways 
but are incapable of providing information about the vertical profile of velocity over the full water column. Autonomous underwater vehicles have the capability to be deployed in a profiling mode, but their station-keeping ability in strong currents has yet to be tested and none of the present designs are capable of travel in the deep (e.g., >3000 db) ocean.

Because none of the available instruments can provide time series of full water column profiles of directly measured absolute velocity, a number of techniques have been developed to calculate absolute velocity profiles by measuring other variables than water velocity. Classical hydrography remains the most commonly used technique; measurements of temperature, salinity, and pressure are used to derive geopotential height anomalies that are differenced to produce relative velocity profiles under the geostrophic approximation (e.g., Pond and Pickard 1983; Johns et al. 1989). One limitation of using hydrography in this manner, however, is that the ship usually moves on to a new site after each profile so this only provides a single snapshot velocity estimate, and that "velocity" is actually an along-track average of just the component of the horizontal velocity that is perpendicular to the ship track. Another limitation is that these geostrophic velocity profiles are determined relative to some assumed "Level of No Motion" (LNM), which is often deduced from tracer distributions or is simply placed at the deepest available level. The well-known problem with the LNM approach, however, is that in many cases there is no LNM. For example, under the Gulf Stream (Johns et al. 1995; Watts et al. 1995) and North Atlantic Current (Meinen et al. 2000; Meinen and Watts 2000; Meinen 2001) the current speeds under the core of the current exceed $10 \mathrm{~cm} \mathrm{~s}^{-1}$ all the way to the bottom. When the LNM approach fails, the relative velocities obtained from the hydrographic measurements must be referenced by some other absolute velocity measurement.

Several different current measurements have been used in the past to provide an absolute reference for the relative velocities: shipboard ADCP (SADCP) measurements usually averaged between hydrographic stations (Pickart and Lindstrom 1994; Saunders and King 1995; Cokelet et al. 1996; Meinen et al. 2000); POGO floats, which provide the vertical-mean horizontal velocity over the upper $\approx 1000 \mathrm{~m}$ (Rossby et al. 1991; Meinen et al. 2000); and lowered ADCP (LADCP) measurements made by an ADCP lowered with the hydrographic package (Beal and Bryden 1999; Donohue et al. 1999); note that the LADCP obtains full water column profiles alone and can also be used without hydrography (e.g., Firing et al. 1998; Donohue et al. 2000). The SADCP and POGO methods suffer from the problem that the geostrophic velocity reference is provided by absolute velocities measured in the layer where the absolute errors and ageostrophic velocities are the largest (e.g., boundary layer currents, cyclostrophic flow), and all three meth- ods provide only a snapshot of the absolute velocity, which is subject to aliasing from tidal and inertial currents. Of course, every measurement technology has its drawbacks, but this difficulty in obtaining absolute velocity profiles has led to a new technique using some nontraditional instruments. More importantly, this new technique can provide time series of daily absolute velocity profiles for at least two years, while the hydrography based methods can provide at most a few snapshot estimates over a month or so.

A recent experiment in the Southern Ocean south of Australia involved an array (Fig. 1) of inverted echo sounders (IESs) and horizontal electric field recorders (HEFRs). The purpose of this paper is to describe how the IES measurements and HEFR measurements obtained during the 2-yr Sub-Antarctic Flux and Dynamics Experiment (SAFDE; Luther et al. 1997) were combined to provide time series of absolute velocity profile estimates. The resulting absolute velocities are compared to concurrent velocity measurements from a current meter, and to a nearby absolute velocity section determined from hydrographic profiles and SADCP measurements.

\section{Data and methods}

Five different measurement systems will be discussed in this paper. Three datasets will be used for comparison to the final HEFR+IES absolute velocity profiles. Conductivity-temperature-depth (CTD) profiles were obtained on the SAFDE deployment cruise on the R/V Melville in March-April 1995. Measurements from an SADCP were also obtained on the Melville cruise. As part of SAFDE an array of current meters was deployed along with the IESs and HEFRs. One current meter mooring was located adjacent to an HEFR site, and the data from the current meter located at a nominal depth of $2000 \mathrm{~m}$ will be compared to the absolute velocities resulting from the HEFR and IES combination. The IES and HEFR measurement systems, while hardly new, are less commonly used in the oceanography community so brief descriptions of the instruments and their measurements are provided here.

\section{a. Inverted echo sounders}

The IES is about $0.6 \mathrm{~m}$ tall and is moored about 1 $\mathrm{m}$ off the ocean bottom. It sends out a $10 \mathrm{-kHz}$ sound pulse and measures the time for the pulse to travel to the ocean surface and back (Watts and Rossby 1977; Chaplin and Watts 1984). Travel time $\tau$ is given by the equation

$$
\tau=2 \int_{0}^{p} \frac{1}{\rho g c} d p^{\prime},
$$

where $\rho$ is density, $g$ is gravity, $c$ is the sound speed, and $p$ is the hydrostatic pressure. Since their development in the 1970s (Rossby 1969; Watts and Rossby 


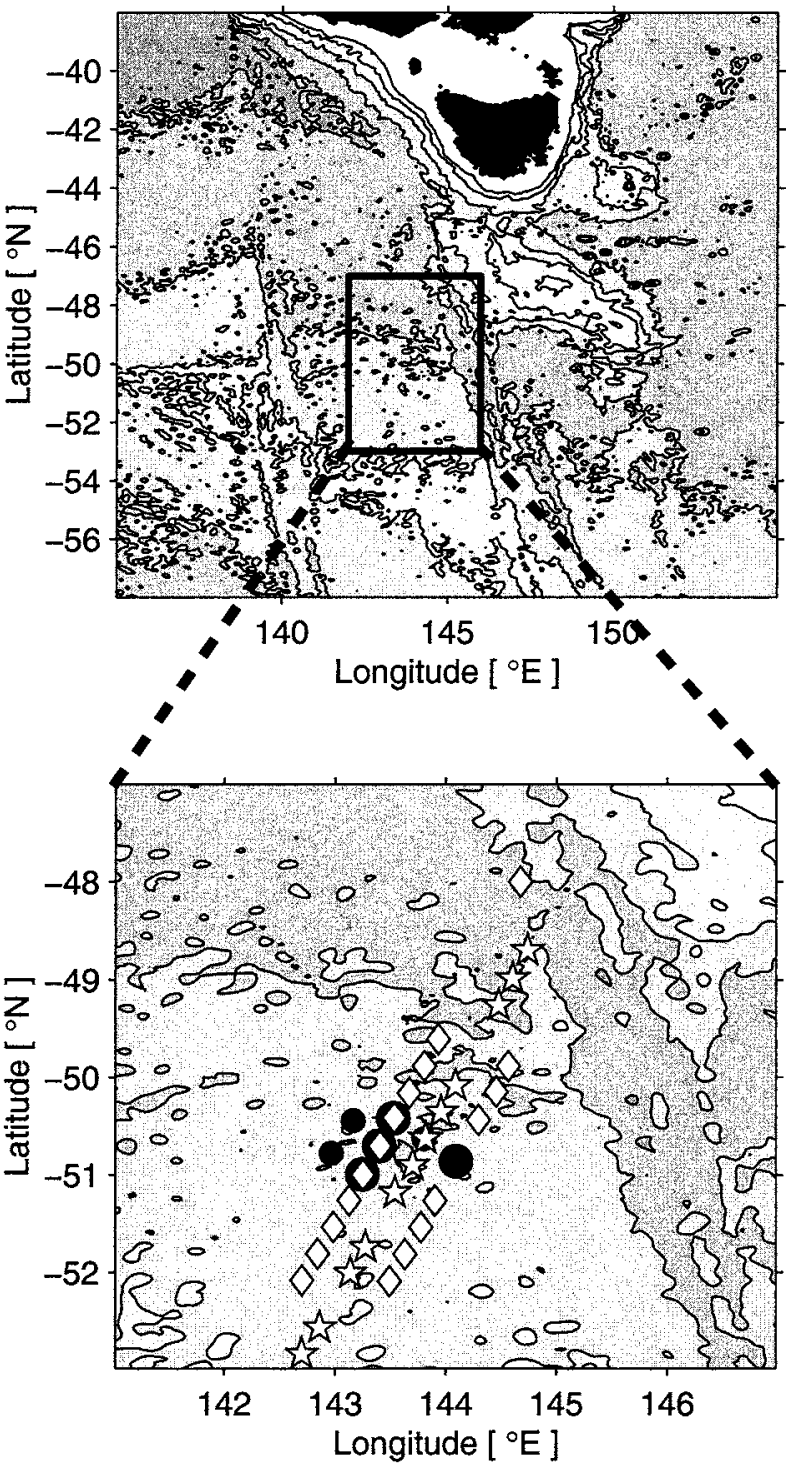

FIG. 1. SAFDE array locations. White diamonds indicate IES locations, white stars indicate HEFR locations, large black dots indicate tall current meter moorings, and small black dots indicate short moorings. Black areas indicate Tasmania and the southern tip of the Australian mainland, gray shading and contours indicate bathymetry at 1000-m intervals radiating away from the land boundaries (Smith and Sandwell 1994). The main instrument array is in water roughly 3000 $4000 \mathrm{~m}$ deep.

1977) IESs have been used to provide estimates of main thermocline depth and other descriptive variables at many locations in the world; examples may be found from the Sargasso Sea (Watts and Rossby 1977), Gulf Stream (Watts and Johns 1982), eastern equatorial Pacific (Chiswell et al. 1986), Gulf Stream/ Sargasso Sea (Hallock 1987), North Atlantic (Trivers and Wimbush 1994; Meinen and Watts 2000), North Pacific/Kuroshio (James and Wimbush 1995), Malvinas, and Brazil Currents (Garzoli and Bianchi 1987), Benguela Current (Garzoli and Gordon 1996),

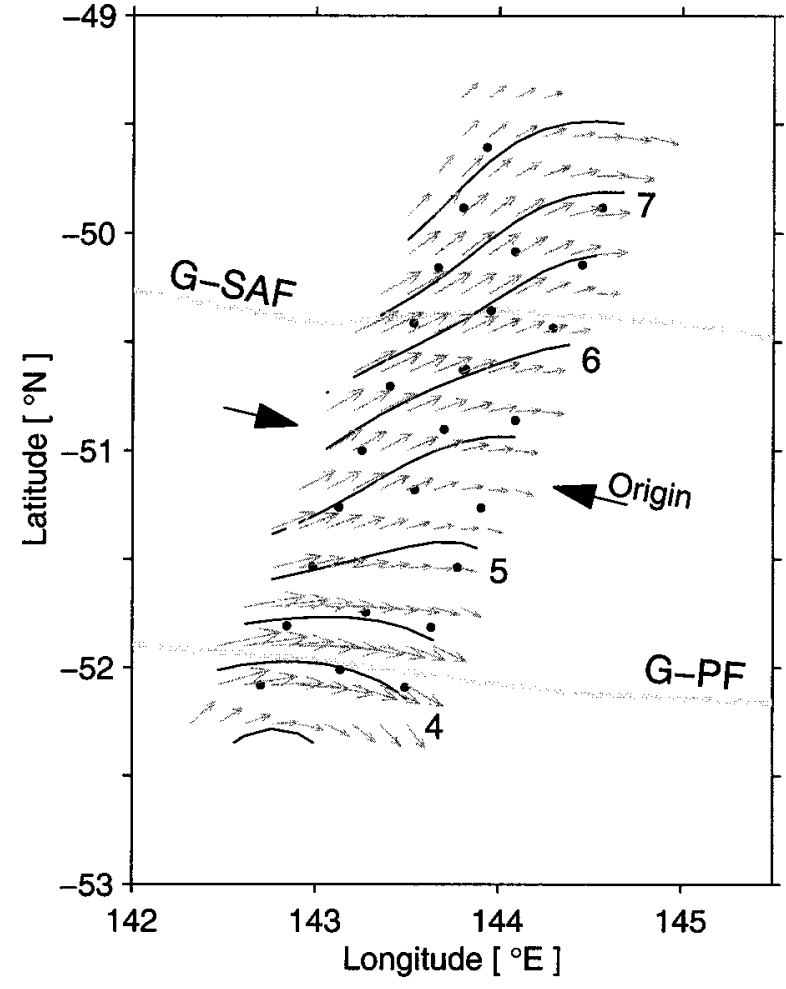

FIG. 2. Time mean (701 days) values of temperature at $500 \mathrm{db}$ (contours every $0.5^{\circ} \mathrm{C}$ ) and surface relative velocity (gray arrows) determined from the IES measurements and the GEM techniques (see text). Temperature contour values are in ${ }^{\circ} \mathrm{C}$. The $6^{\circ} \mathrm{C}$ isotherm crosses $500 \mathrm{db}$ near the core of the SAF. Largest gray vectors represent a speed of about $40 \mathrm{~cm} \mathrm{~s}^{-1}$. All moored instruments are shown as black dots, see Fig. 1 for designation of mooring types. Large black arrows outside the array indicate the axis for the origins required for Figs. 5 and 6. The mean SAF and PF positions determined by Gille (1994) from Geosat sea surface height gradients for 1986-89 are shown (GSAF and G-PF, respectively).

and Hawaii (Chiswell 1994). These applications required that sufficient hydrographic data from the neighboring region were available to determine the characteristic relationships between $\tau$ and thermocline depth, etc., as well as to provide uncertainty estimates. Subsequent studies extracted additional information from $\tau$ by interpreting it as proportional to the amplitude of the first baroclinic mode (Pickart and Watts 1990), or by assuming parallel isotherms within the thermocline (He et al. 1998).

Recently an empirical method, referred to as the "gravest empirical mode" (GEM) technique, has been developed that allows the IES-measured $\tau$ to estimate the full water column profiles of temperature, salinity, and specific volume anomaly (Meinen and Watts 2000; Watts et al. 2001). In brief, characteristic relationships for temperature, salinity, and specific volume anomaly as functions of pressure and $\tau$ were derived from historical hydrography, producing the GEM fields $T_{G}(p$, $\tau), S_{G}(p, \tau)$, and $\delta G(p, \tau)$, respectively. Consequently, a single measurement of $\tau$ from an IES combined with 


\section{Zonal velocities at the site of HEFR 9}
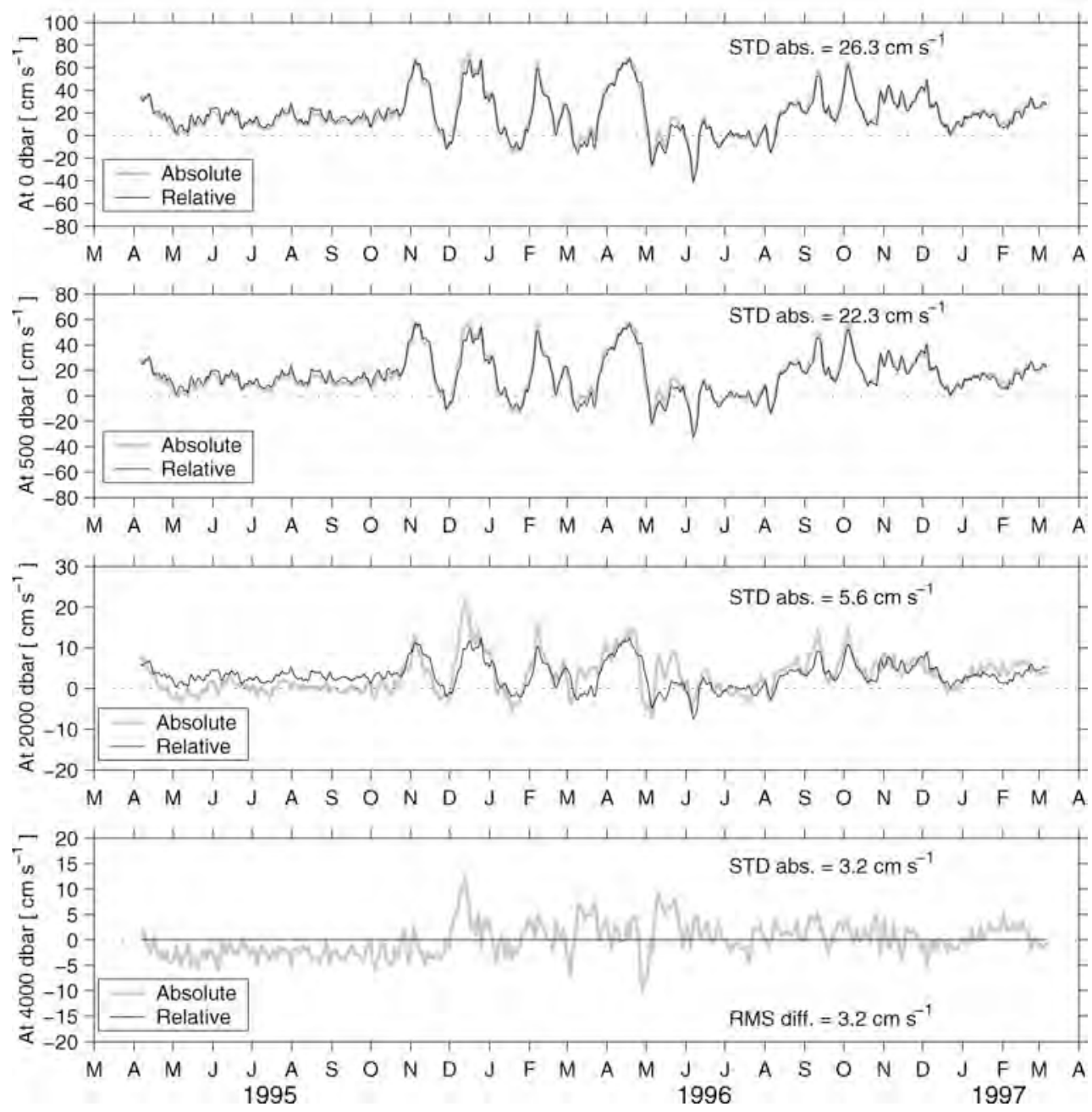

FIG. 3. Zonal velocity comparison between absolutely referenced velocities (gray lines) and velocities relative to $4000 \mathrm{db}$ (thin black lines) at HEFR site 9 (the sixth star from the top of the array in Fig. 1). Each panel represents a different pressure level, from the surface to $4000 \mathrm{db}$ as noted by the ordinate labels. Standard deviation of the absolute velocity is noted in the upper-right corner of each panel. Rms difference between absolute and relative velocities is shown in the bottom panel; it is by definition exactly the same for the other panels.

the hydrography-based GEM fields provides an estimate of the vertical profiles of dependent variables $T, S$, and $\delta$. For the GEM technique to work, there must be sufficient hydrography within the study region to characterize the mesoscale variability, and the temperaturesalinity relationships must be temporally stable (but not necessarily tight). Watts et al. (2001) demonstrate that the GEM technique is effective in the SAFDE region, capturing, for example, at least $95 \%$ of the temperature and specific volume anomaly variance throughout the thermocline levels. The technique even captures $95 \%$ of the salinity variance in this range, because the temperature-salinity relationship is temporally stable in this region (Watts et al. 2001).
The IESs used in the SAFDE experiment made $\tau$ measurements on an hourly basis. At one location, the easternmost current meter mooring (Fig. 1), the temperatures from the current meters were used to generate synthetic IES $\tau$ values every hour following the methods presented in Meinen and Watts (2000). The real and synthetic hourly $\tau$ data were low-pass filtered using a 72-h second-order Butterworth filter passed forward and backward to avoid phase shifting. The IES data were then subsampled to once per day at noon Universal Coordinated Time. Applying the GEM technique to the subsampled IES data produces full water column profiles of $T, S$, and $\delta$ above each IES each day of the 2yr experiment. The GEM technique also provides an 


\section{Meridional velocities at the site of HEFR 9}
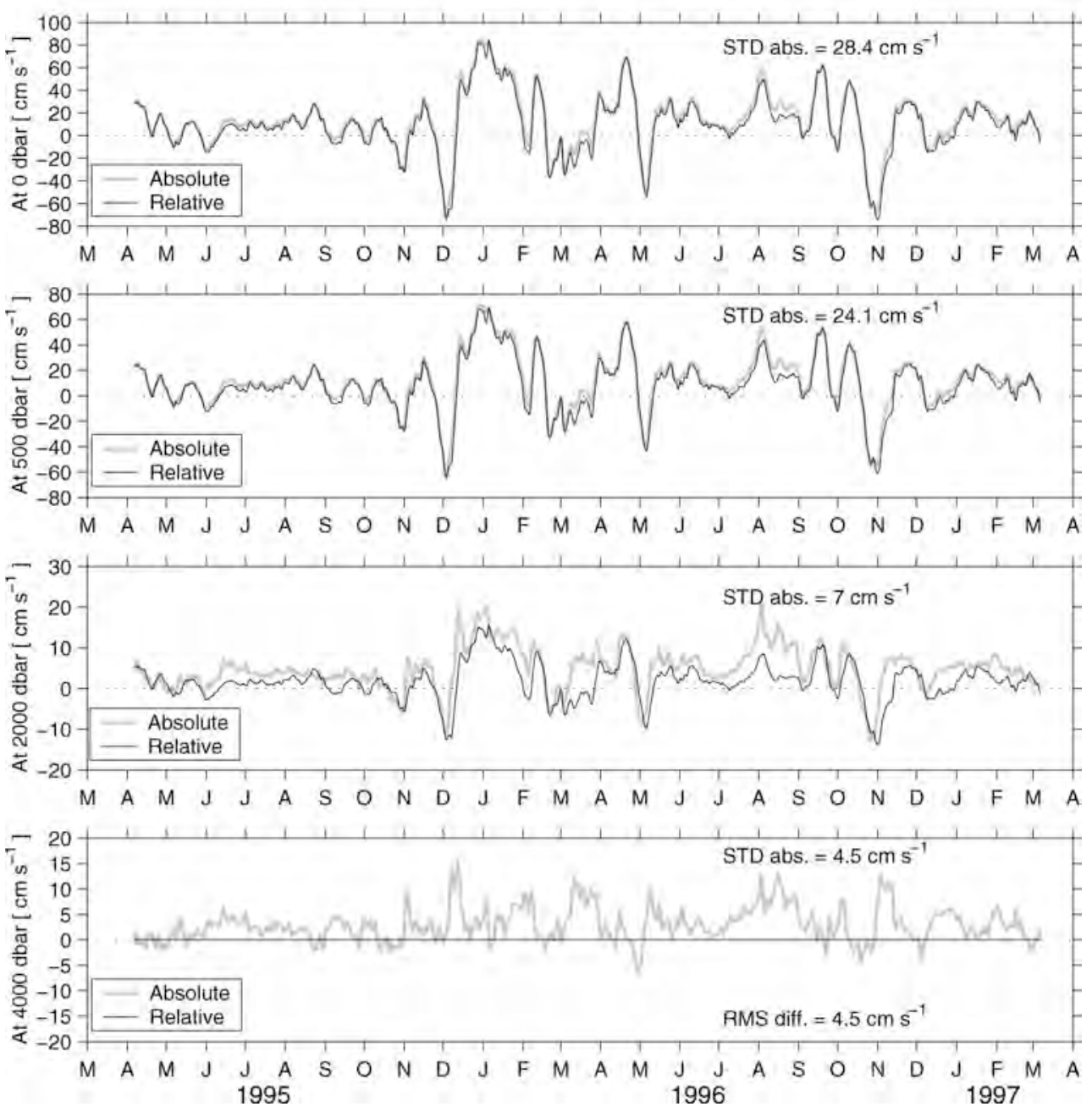

FIG. 4. Same as Fig. 3 except for the meridional component of the velocity.

estimate of the accuracy of these profiles based on the scatter in the hydrography used to prepare the GEM fields (Meinen and Watts 2000; Watts et al. 2001). Below the seasonal thermocline, the rms differences between CTD-measured temperatures and GEM-predicted temperatures were less than $0.4^{\circ} \mathrm{C}$ within the main thermocline and less than $0.1^{\circ} \mathrm{C}$ below the main thermocline.

The specific volume anomaly profiles determined by the IES + GEM can be integrated vertically to provide profiles of geopotential height anomaly $(\Delta \Phi)$. When a pair of IESs are available, the $\Delta \Phi$ profiles at the two sites can be differenced to find the component of the relative velocity perpendicular to the line between the sites via the standard dynamic method (Meinen and Watts 2000). When a two-dimensional array of IESs is deployed, then this method can provide profiles of both horizontal components of the relative velocity.

\section{b. Horizontal electric field recorders}

Seafloor measurements of the horizontal electric field (HEF) have been obtained since the 1960s both for estimating conductivity in earth's mantle (with the high frequency, $>1 \mathrm{cpd}$, signals) and for observing ocean flow (e.g., Cox et al. 1970; Filloux 1982; Luther et al. 1991; Chave et al. 1992, 1997). The low-frequency $(<0.5 \mathrm{cpd}) \mathrm{HEF}$ in the ocean is dominated by motional induction caused by the motion of conductive seawater through earth's magnetic field. Sanford (1971) and Chave and Luther (1990) derive a theoretical relationship between the HEF and the horizontal water velocity that is valid for a flat-bottomed ocean when the length scale of the flow is much larger than the water depth; Sanford also considered the perturbation influence of mild topography. These studies showed that the HEF is proportional to the seawater conductivity-weighted, vertically averaged horizontal water velocity as follows: 


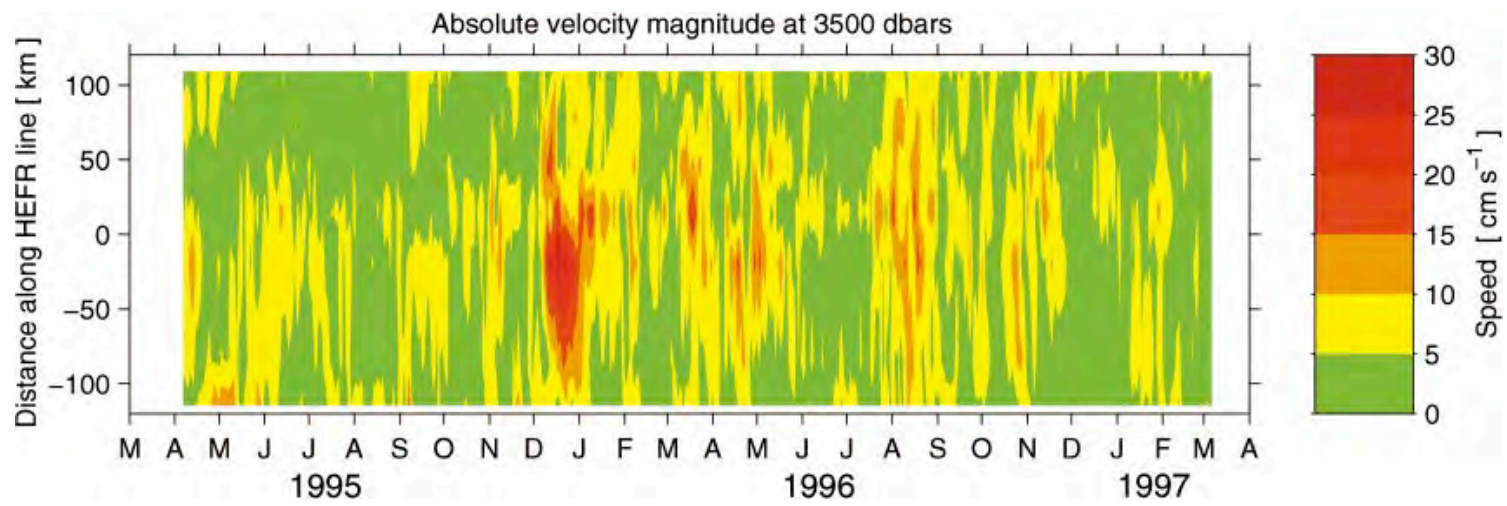

FIG. 5. Absolute velocity magnitude at $3500 \mathrm{db}$ near the ocean bottom. Velocities are determined at the sites of HEFR moorings and the $y$ axis denotes the distance (along the HEFR line) measured from an arbitrary origin defined in Fig. 2.

$$
\begin{aligned}
\left\langle\mathbf{V}_{h}(t)\right\rangle^{*} & =\frac{\int_{-H}^{0} \sigma\left(z^{\prime}, t\right) \mathbf{V}_{h}\left(z^{\prime}, t\right) d z^{\prime}}{\int_{-H}^{0} \sigma\left(z^{\prime}, t\right) d z^{\prime}} \\
& =\left\langle\mathbf{V}_{h}(t)\right\rangle+\frac{\int_{-H}^{0} \sigma\left(z^{\prime}, t\right) \mathbf{V}_{h}^{\prime}\left(z^{\prime}, t\right) d z^{\prime}}{\int_{-H}^{0} \sigma\left(z^{\prime}, t\right) d z^{\prime}},
\end{aligned}
$$

where angle brackets \langle\rangle denote a vertical average; $\left\langle\mathbf{V}_{h}(t)\right\rangle^{*}$ is the conductivity-weighted, vertically averaged horizontal water velocity derived from the HEFs; $\sigma(z, t)$ is the seawater electrical conductivity, and $\mathbf{V}_{h}(z$, $t$ ) is the horizontal water velocity, which is divided into a vertical average $\left\langle\mathbf{V}_{h}(t)\right\rangle$ and a perturbation from the vertical average $\mathbf{V}_{h}^{\prime}\left(z^{\prime}, t\right)$. The second term on the right in (2) is a conductivity-weighting bias that is estimated and removed from $\left\langle\mathbf{V}_{h}\right\rangle^{*}$ to get $\left\langle\mathbf{V}_{h}\right\rangle$.

In addition, Chave and Luther (1990) demonstrate that an HEF measurement also represents a horizontal spatial average of the water velocity over a circular area of radius about one water depth. Successful demonstrations of this theoretical relationship have been reported by Luther et al. (1991) and Chave et al. (1997) for point seafloor HEF measurements. Sanford (1986) and Larsen (1992) summarize analogous results for moving observation platforms and long seafloor cables, respectively.

The self-contained, seafloor-based horizontal electric field recorder (HEFR) is a 1.5 -m-tall instrument described by Filloux (1987), Petitt et al. (1992), and Bailey et al. (2001). The HEFR records the electric potential across two orthogonal 3-m-span salt bridges using mechanical electrode switching to eliminate the effect of electrode drift. The sampling rate was selected to provide one full measurement 16 times per hour during SAFDE. The orientation of the HEFR with respect to magnetic north, as well as instrument tilt, was internally recorded by the SAFDE instruments using mechanical compasses. Unfortunately, after recovery all of the HEFR compasses were determined to have locked due to the extreme inclination $\left(>80^{\circ}\right)$ of earth's magnetic field in the SAFDE region. In addition, HEF amplitudes varied by $40 \%$ between sites, but these differences were not instrument related. Further investigation showed the amplitude differences to be due to galvanic distortion of the motional electric field by the rough bathymetry in the SAFDE region. Identified by site- and horizontal component-dependent variations of the electric field amplitude, galvanic distortion is a well-understood phenomenon in electromagnetic geophysics. Standard approaches have been developed to remove it from field measurements (e.g., Groom and Bailey 1989; Chave and Smith 1994). While galvanic distortion has not been observed in other motional induction measurements, it can be expected to occur in regions where seafloor relief is large.

The frequency-independent galvanic distortion was removed from the SAFDE data using the high-frequency (>6 cpd) electric fields that are dominantly of polar geomagnetic substorm/auroral origin at high latitudes. These fields have high horizontal coherence at the scale of the SAFDE array and exhibit strong linear polarization. Intersite electric field transfer functions were first estimated using a bounded influence approach (Chave and Thomson 2001, manuscript submitted to Geophys. J. Int.) to remove bias caused by the highly nonstationary and non-Gaussian nature of geomagnetic field variations. The transfer functions were then decomposed using a modification of the method of Chave and Smith (1994) as described by Chave et al. (2002, manuscript submitted to J. Atmos. Oceanic Technol., hereafter CLM). This approach removed all galvanically induced field rotations and aligned all of the measurements in a relative sense but left a time-independent ambiguity in both absolute orientation and amplitude. The absolute HEF orientation and magnitude were determined at one HEFR location (site 9, sixth star from top in Fig. 1) by comparing (i) the corrected low-frequency $(<0.5 \mathrm{cpd})$ HEF measurements to (ii) a synthetic HEF record ob- 

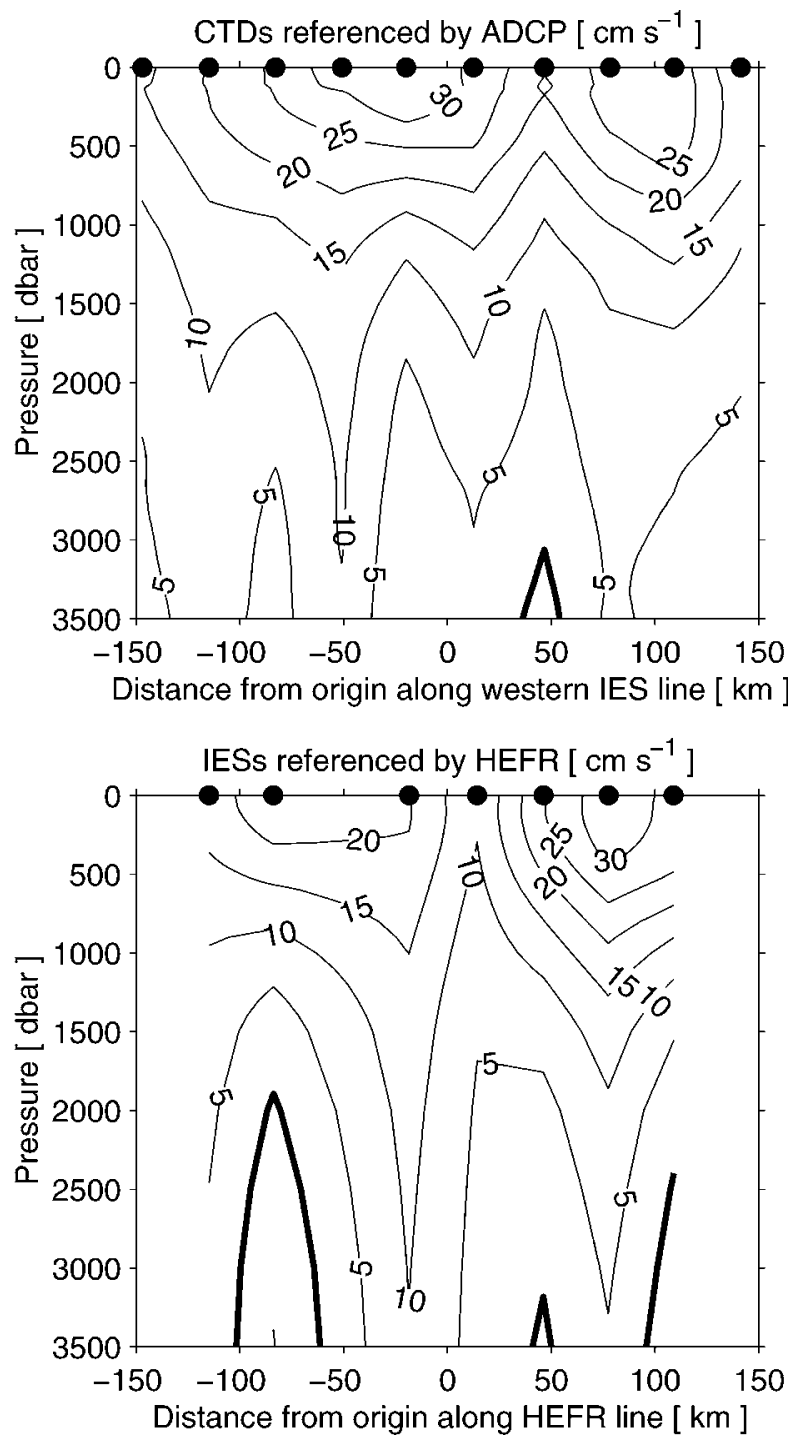

FIG. 6. Comparison of two absolute velocity sections obtained in Apr 1995. (top) Absolute velocity perpendicular to the CTD section (which was parallel to the principal SSW-NNE axis of the HEFRIES array), obtained using geostrophic velocities calculated from the CTD section combined with SADCP measurements to provide the absolute reference. The section was obtained along the western line of IESs. (bottom) Section of absolute velocity perpendicular to the HEFR line estimated using the HEFR + IES methods described in the text. This section was obtained along the HEFR line, roughly $30 \mathrm{~km}$ east and parallel to the CTD section. Velocities are in $\mathrm{cm} \mathrm{s}^{-1}$ with bold line denoting zero velocity. Black dots along upper axes denote either (top) CTD sites or (bottom) HEFR sites.

tained by combining the IES relative velocities and conductivity profiles at the site with the 2000-m absolute velocity measurements obtained by a current meter moored about $1 \mathrm{~km}$ away. This low-frequency orientation at HEFR site 9, combined with the high-frequency transfer functions, orients all of the HEFRs relative to true north, thus correcting for the compass failures. The correct amplitudes at the remaining sites were obtained assuming a linear dependence of the high-frequency
( $>6$ cpd) standard deviation on distance from the geomagnetic dip pole, consistent with geophysical practice. Further details may be found in CLM.

After correction of the HEF measurements as discussed above, they were converted to units of vertically averaged water velocity using the International Geomagnetic Reference Field 1995 (Quinn et al. 1997) corrected for secular variation to the middle of the SAFDE epoch. The currents were low-pass filtered and subsampled daily like the IES $\tau$ measurements discussed previously.

At this point the HEF-derived currents still contain a small conductivity bias as per (2). Because seawater electrical conductivity varies only weakly with depth at high latitudes, it probably can be ignored in the interpretation of the HEF as vertically averaged current (in SAFDE it was generally $\pm 1 \%-4 \%$ of the actual velocity signals, highest at the north side of the array where stratification was strongest). However, in order to be as accurate as possible, for those HEFRs within the IES array, a conductivity weighting correction was estimated with relative velocities determined as described in the next section and conductivity profiles estimated from the IES $\tau$ fields in conjunction with a conductivity GEM.

The next section describes how profiles of relative velocity are derived from the IES $\tau$ measurements and how the relative velocity is then made absolute by the inclusion of the HEF-derived vertically averaged velocities.

\section{c. Combining the HEFR and IES data}

SAFDE was designed with two lines of IESs spanning a single line of HEFRs, with a few HEFRs and one IES extending beyond the main array (Fig. 1). In order to use the HEFR measurements to reference the relative velocities from the IESs it was necessary to combine the two datasets in a dynamically consistent way. Currents were calculated geostrophically from the estimated zonal and meridional gradients of geopotential height anomaly $\Delta \Phi$. For this purpose, the field $\Delta \Phi(p, \tau)$ was calculated by vertically integrating $\delta_{G}(p, \tau)$, retaining the indexing by $\tau$. The lateral gradients were estimated at each depth level as $\partial \Delta \Phi / \partial x=(\partial \Delta \Phi / \partial \tau)(\partial \tau / \partial x)$ and $\partial \Delta \Phi / \partial y=(\partial \Delta \Phi / \partial \tau)(\partial \tau / \partial y)$. From the IES measurements, both $\tau$ and the horizontal gradients $\partial \tau / \partial x$ and $\partial \tau /$ $\partial y$ were mapped to the HEFR sites by optimal interpolation (e.g., Bretherton et al. 1976) using a correlation scale of $60 \mathrm{~km}$ (scale chosen based on observations of cross correlations between IES sites).

The resulting profiles of $\partial \Delta \Phi / \partial x$ and $\partial \Delta \Phi / \partial y$ were converted into geostrophic velocities relative to a level of no motion at $4000 \mathrm{db}$ using the standard dynamic method (e.g., Pond and Pickard 1983). The level of no motion of $4000 \mathrm{db}$ was chosen because that level was near to the deepest level at which any of the IES or HEFR instruments were deployed, and enough CTD sta- 

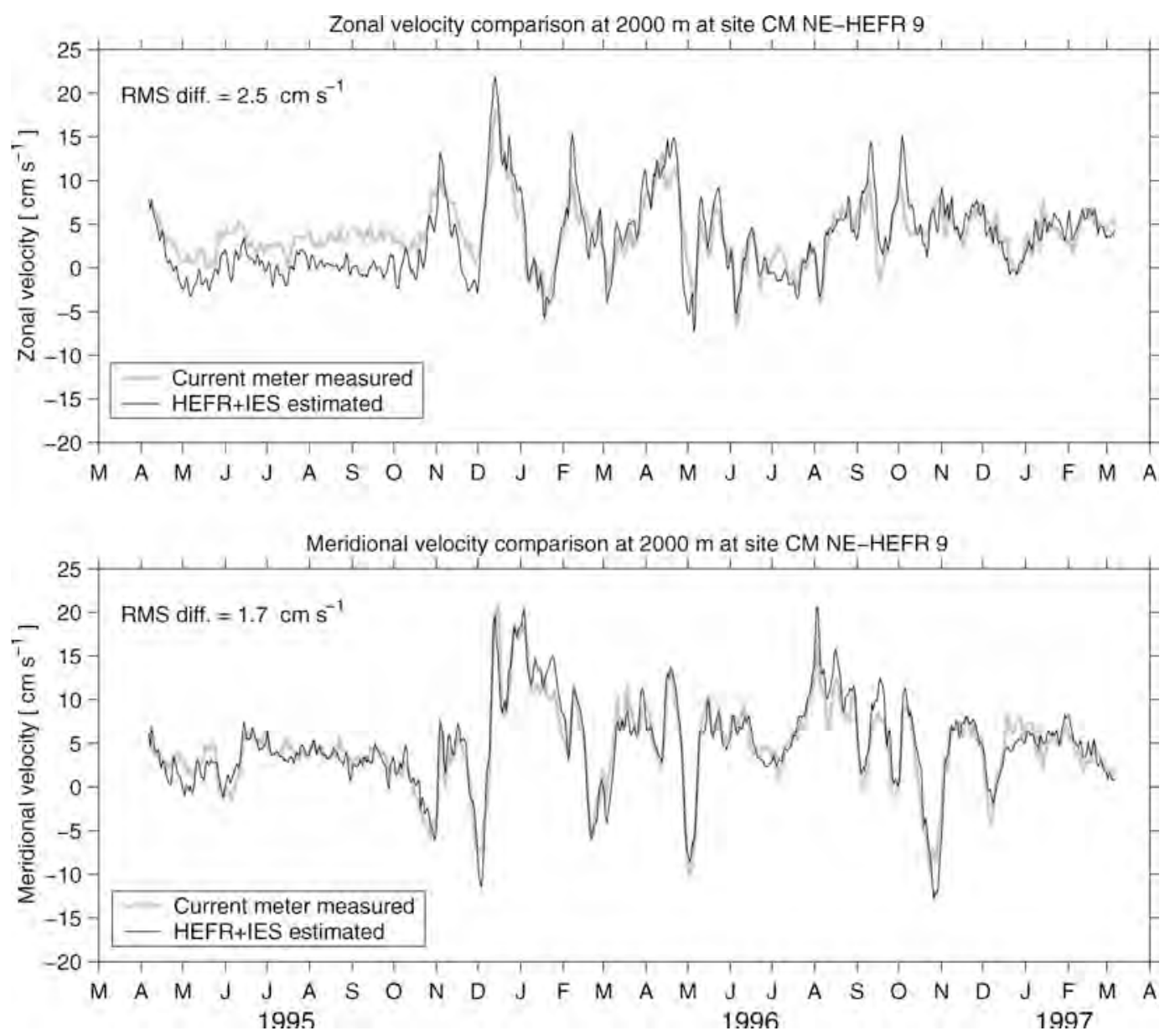

FIG. 7. Comparison between the directly measured velocities from the current meter at $2000 \mathrm{~m}$ at site CM NE and the HEFR+IES velocities at $2000 \mathrm{~m}$ at HEFR site 9, which was about a kilometer away. (top) Zonal component. (bottom) Meridional component. Rms differences over the length of the time series are shown for each panel.

tions extended to $4000 \mathrm{db}$ to determine good estimates of the GEM field.

Estimates of ocean temperature were obtained using the IES measurements of $\tau$ and the hydrography-based $T_{G}(p, \tau)$. Figure 2 presents a map of the mean IESestimated temperature at $500 \mathrm{db}$ and the mean relative velocity at the surface (averaged over the length of the experiment, 701 days). The mean baroclinic component of the Antarctic Circumpolar Current flowing along the Subantarctic Front (SAF) crossed the array somewhat obliquely tending to flow from the southwest toward the northeast. This path direction is consistent with $2-\mathrm{yr}$ mean velocities from moored current meters in this area just prior to SAFDE (Phillips and Rintoul 2000) but is not clearly present in the map of the mean SAF position presented by Gille (1994) from an analysis of the 198689 Geosat sea surface height gradients. The mean latitude from Gille's analysis, however, is in good agreement with that found by the SAFDE array (Fig. 2).

In the southern portion of the SAFDE array the mean baroclinic flow crossed nearly orthogonal to the array, being strongest at a latitude consistent with the mean position of the polar front (PF) defined by Gille (1994). In contrast, this position for the PF is about $400 \mathrm{~km}$ north of the mean PF position estimated on the basis of satellite sea surface temperature, and is $250-500 \mathrm{~km}$ north of the position estimated from historical water properties (Moore et al. 1999). Between the SAF and $\mathrm{PF}$, at about $51.5^{\circ} \mathrm{S}$, Fig. 2 shows a relative minimum in current speed less than half the current speeds in the cores of the SAF and PF. Of course the barotropic component of the velocity, defined here as the near-bottom velocities, is invisible to the IESs when they are used alone. As we will now show this is an important consideration.

The IES and HEFR velocities were combined by adding depth-independent (position and time dependent) vector currents to the IES relative velocity profiles to shift their vertical means to equal those of the HEFR measured vertical means. The vertical average was calculated from the surface to the depth of each respective HEFR. The reference velocity was determined separately for the zonal and meridional components of the velocity for each day of the experiment. The combined 


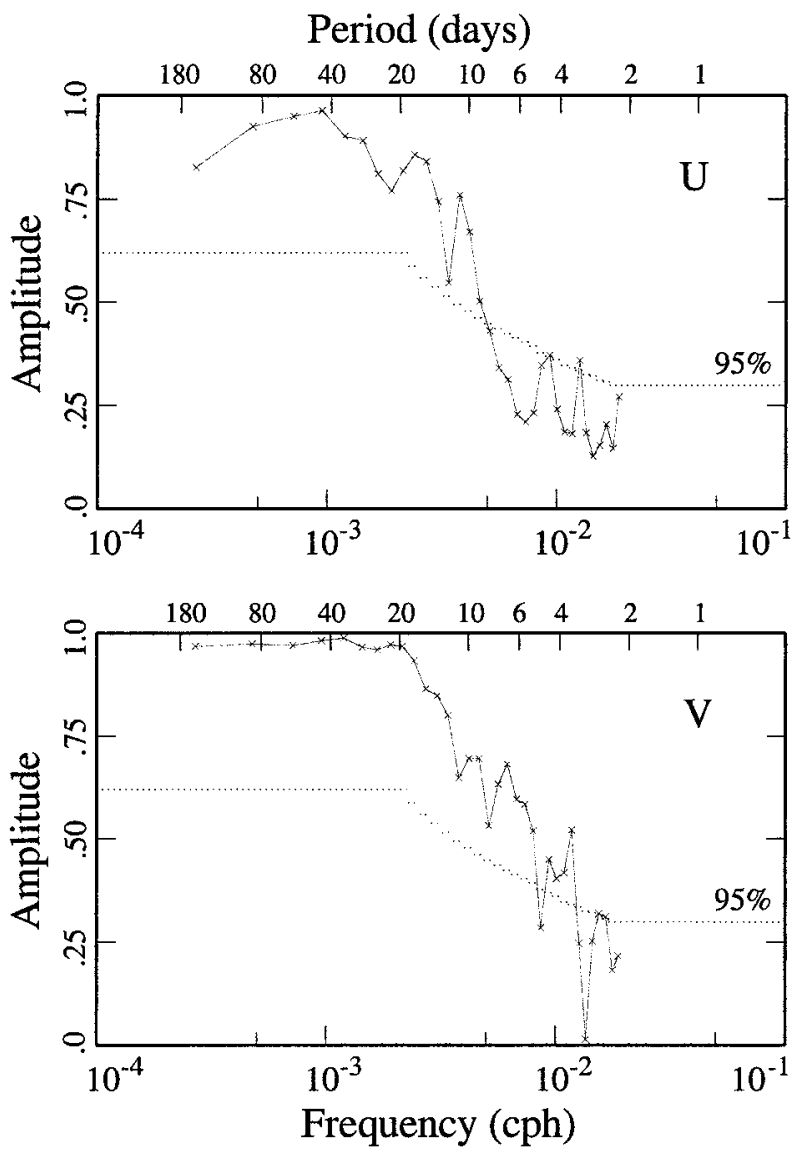

FIG. 8. Coherence amplitude between time series shown in Fig. 7. (top) Coherence amplitude between zonal velocity components. (bottom) Coherence amplitude between meridional velocities. Dotted lines indicate $95 \%$ level of zero significance.

datasets provide time series of absolute velocity profiles at each of the seven HEFRs within the IES array. [Meinen and Watts (2000) develop an alternative method for referencing IES relative velocities observed in the North Atlantic Current. They utilize deep current meter and bottom pressure sensor measurements to estimate abyssal velocities. Their technique provides absolute velocity estimates with comparable accuracies to the method presented here.] Figure 3 presents the zonal velocity on four pressure levels at HEFR site 9, and Fig. 4 shows the meridional velocities on the same four levels. While the differences between absolute and relative velocities at the surface and $500 \mathrm{db}$ are small compared to the observed signals, at depths of $2000 \mathrm{db}$ and deeper the differences are qualitatively and quantitatively important. At $4000 \mathrm{db}$, only the barotropic component remains nonzero, exhibiting what would be missed without the HEFR referencing.

Figure 5 illustrates the spatial and temporal variability of the deep velocities observed along the HEFR line (3500 db was chosen as an example). While the experiment-length-mean speeds are generally $2 \mathrm{~cm} \mathrm{~s}^{-1}$ or less, bottom speeds were routinely over $5 \mathrm{~cm} \mathrm{~s}^{-1}$ throughout the array region. Speeds peaked at $29 \mathrm{~cm} \mathrm{~s}^{-1}$ and often exceeded $10-15 \mathrm{~cm} \mathrm{~s}^{-1}$ for periods of weeks and longer. For example, in December 1995 for nearly a month the $3500-\mathrm{db}$ speeds exceeded $15 \mathrm{~cm} \mathrm{~s}^{-1}$ over most of the southern half of the array (Fig. 5). A bottom speed of $5 \mathrm{~cm} \mathrm{~s}^{-1}$ corresponds to a transport of nearly $10 \mathrm{~Sv}$ (1 $\mathrm{Sv} \equiv 10^{6} \mathrm{~m}^{3} \mathrm{~s}^{-1}$ ) when applied over the full water column and a 50-km horizontal range. By applying a level of no motion near the bottom (as is common practice in the Southern Ocean) the total transport in December 1995 could have been underestimated by about $45 \mathrm{~Sv}$.

\section{Comparisons with independent measurements}

While the accuracies of both IES measurements of geostrophic relative velocity (e.g., Meinen and Watts 2000) and HEFR measurements of vertically averaged absolute horizontal velocities (e.g., Luther et al. 1991) have been independently verified, SAFDE data provide the opportunity to compare the HEFR + IES absolute velocity profiles with other independent measurements of absolute velocities. These comparisons should be considered "consistency checks," rather than rigorous attempts at validation, because the additional data available for comparisons in this experiment are sparse.

A CTD section was conducted along the western line of IESs about $30 \mathrm{~km}$ west of the HEFR line on a parallel course. Geostrophic relative velocities were obtained by the standard method using the CTD profiles, and SADCP measurements were used to provide the absolute references for them. The referencing was completed by spatially integrating the measured ADCP velocities first vertically between 50 and $250 \mathrm{~m}$ and then horizontally over the roughly $33 \mathrm{~km}$ between the CTD sites (Pickart and Lindstrom 1994; Cokelet et al. 1996; Meinen et al. 2000). The resulting absolute velocity section (Fig. 6, top) showed two maxima in the eastward flow near $51.5^{\circ} \mathrm{S}$ and near $50^{\circ} \mathrm{S}$ with a local minimum (but still eastward flow) between them. About $30 \mathrm{~km}$ to the east the HEFR + IES absolute velocities, averaged over the same 5-day period as the CTD section and having roughly the same $(\approx 37 \mathrm{~km})$ horizontal resolution, also captured double peaks in the eastward velocities and demonstrated magnitudes that were nearly the same as those observed by the CTD/ADCP section (Fig. 6, bottom). The horizontal maps of $6^{\circ} \mathrm{C}$ isotherm depth from the same time period (not shown) indicate some turning of the fronts between the locations of the CTD and HEFR sections. This turning of the path can account almost entirely for the disparities between the two (horizontally separated) absolute velocity sections.

A more exacting comparison of the time series of HEFR + IES absolute velocities is with directly measured velocities from SAFDE moored current meters at the same locations as the HEFRs. Unfortunately, because of a number of current meter losses, only one current meter is available at a nearly coincident site for 
comparison with the HEFR + IES absolute velocities. This current meter was moored at a nominal depth of $2000 \mathrm{~m}$ near the middle of the SAFDE array (CMNE, latitude $-50.6288^{\circ} \mathrm{N}$, longitude $143.8048^{\circ} \mathrm{E}$, indicated in Fig. 1 by the small black circle coincident with the sixth star from the top of the array, the star denoting HEFR 9). The HEFR + IES absolute velocity at $2000 \mathrm{~m}$ above the HEFR site was extracted for the comparison (Fig. 7). The correlation length scale used in the optimal interpolation of the IES geopotential heights $(60 \mathrm{~km})$ results in a horizontal smoothing of the HEFR+IES absolute velocities, while the current meter-measured velocities are not subject to such smoothing. Nevertheless, the agreement between the two different absolute velocity time series is quite good, with a root-meansquare (rms) difference of $2.5 \mathrm{~cm} \mathrm{~s}^{-1}$ for the zonal velocity component and $1.7 \mathrm{~cm} \mathrm{~s}^{-1}$ for the meridional velocity component. As noted earlier in section 2, the velocity measurements from this current meter were used in the time-independent HEFR calibrations. As such these rms differences may be somewhat artificially low; however, without additional independent data an accurate estimate of the "independent" rms differences cannot be obtained. Nevertheless, the time-dependent variability comparisons that are shown next are completely independent. Furthermore, the expected accuracy of the HEFR + IES absolute velocities at $2000 \mathrm{db}$ (derived in the appendix) is approximately $3 \mathrm{~cm} \mathrm{~s}^{-1}$, indicating that the differences observed in Fig. 7 are about equal to the expected errors in the method.

The coherence amplitudes between the time series in Fig. 7 are shown in Fig. 8. The coherence amplitude for the zonal velocity component is statistically significant for periods greater than about 9 days, while the coherence between the meridional velocities is significant down to periods of 3-4 days. The coherence amplitudes in Fig. 8 compare favorably with those found in a separate experiment by Luther et al. (1991) between HEFR measurements of the vertical integral of horizontal currents and a vertical integration of the horizontal currents measured by six current meters distributed throughout the water column. The coherence phases associated with the amplitudes of Fig. 8 indicate no significant phase shifting between the velocity components.

\section{Summary and conclusions}

This paper has presented a method for obtaining time series of full water column profiles of absolute velocity by combining the measurements of the inverted echo sounder with the measurements of the horizontal electric field recorder. An array of IESs provides profiles of geostrophic relative velocity by applying GEM techniques (Meinen and Watts 2000; Watts et al. 2001) to obtain profiles of geopotential height anomalies, which are then horizontally differenced using the standard dynamic method to provide relative velocities. The HEFR provides estimates of the vertically averaged horizontal velocity in the overlying water column. This verticalmean absolute velocity can be used to reference the relative velocity profiles from the IES, providing profiles of absolute velocity.

Comparisons with independent absolute velocity estimates from two sources were presented. Relative geostrophic velocities based on the measurements of a CTD section $30 \mathrm{~km}$ west of the HEFR instruments were referenced using SADCP measurements to provide a section of absolute velocity, which closely resembled the concurrent HEFR + IES absolute velocity section, in current strength and structures, considering the horizontal offset $(30 \mathrm{~km})$ between the two sections. A direct comparison with measured velocities observed by a current meter moored at about $2000 \mathrm{~m}$ depth roughly $1 \mathrm{~km}$ from the site of a HEFR mooring demonstrated agreement to within $2.5 \mathrm{~cm} \mathrm{~s}^{-1} \mathrm{rms}$ for the zonal velocity component and $1.7 \mathrm{~cm} \mathrm{~s}^{-1} \mathrm{rms}$ for the meridional velocity component. These rms differences could be explained entirely as the difference between point current measurements and currents averaged laterally over 30-40-km intervals, even if the measurements themselves were error-free. The favorable comparisons indicate that the combination of the HEFR and IES provides a powerful method for obtaining time series of absolute velocity profiles.

Acknowledgments. The authors thank Che Sun for providing some preliminary SAFDE GEM fields, Steve Rintoul for providing most of the hydrography used in this study, and Sarah Gille for providing the exact positions of the SAF and PF for the SAFDE region derived as described in Gille (1994). The anonymous reviewers provided a number of helpful suggestions for improving this paper. This work was completed under NSF Grants OCE9204040, OCE9204041, OCE9204063, OCE9204113, OCE9911974, and OCE9912320.

\section{APPENDIX}

\section{Velocity Accuracy}

The rms accuracy of the absolute geostrophic velocities is a function of the two sources of error in our calculation: error in the IES-derived geostrophic velocities, and error in the HEFR-measured absolute vertically averaged horizontal velocities. In order to estimate the error in the former, Watts et al. (2001) compared the IES-derived geostrophic velocities relative to 2000 or $3200 \mathrm{db}$ against measured velocity differences between current meters at 300,600, and $1000 \mathrm{db}$ relative to current meters at 2000 or $3200 \mathrm{db}$. The rms difference between the two sets of relative velocities was 7,5 , and $3 \mathrm{~cm} \mathrm{~s}^{-1}$ at depths of 300,600 , and $1000 \mathrm{db}$, respectively. These differences include both measurement error and geophysical noise (because the current meters 
are point measurements while the IES-derived velocities represent spatial averages over roughly $30 \mathrm{~km}$ ), and as such they provide a "worst case" error bar for the IESderived geostrophic relative velocities.

Based on comparison with independent measurements in previous experiments (Luther et al. 1991), the HEFR measurement of the vertical integral of horizontal current is accurate to better than $1 \mathrm{~cm} \mathrm{~s}^{-1}$. However, because of the added complexity of recovering the vertically averaged horizontal currents from the SAFDE HEFRs (CLM), the HEFR vertically averaged currents are estimated to be accurate to within $3 \mathrm{~cm} \mathrm{~s}^{-1}$.

The absolute velocity estimates resulting from the combination of the IES and HEFR velocities are accurate to within the square root of the sum of the squares of these two error sources since the error sources are independent of one another. For the daily absolute velocity at depths of $300,600,1000$, and $2000 \mathrm{db}$ the estimated error bars are $8,6,4$, and $3 \mathrm{~cm} \mathrm{~s}^{-1}$, respectively.

There are additional sources of error that have not been described here, primarily because they are believed to be small $\left(<2 \mathrm{~cm} \mathrm{~s}^{-1}\right)$. For example, because HEFR measurements are the vertical average of the true velocity, including both geostrophic and ageostrophic components, using these velocities to reference the IES relative velocities, which by definition contain only the geostrophic component, could lead to an error. Most ageostrophic velocity signals will have a small effect on the vertically averaged horizontal velocity. For example, Ekman velocities, which can be strong both near the surface and near the bottom, will have little effect because they are confined to depth ranges that are small compared to the full water column depth. Ekman velocities of $20 \mathrm{~cm} \mathrm{~s}^{-1}$ averaged over the upper $100 \mathrm{~m}$ would result in a $0.5 \mathrm{~cm} \mathrm{~s}^{-1}$ impact on the $4000-\mathrm{m}$ vertical average. The impact of other ageostrophic velocities, such as the cyclostrophic term, on the vertical averaged velocity are difficult to quantify, but they should not exceed $5 \%$ of the vertically averaged velocity. Other sources of error are discussed in the papers that describe the IES and HEFR processing (Meinen and Watts 2000; Watts et al. 2001; CLM); these other sources of error are believed to be much smaller $(<2$ $\left.\mathrm{cm} \mathrm{s}^{-1}\right)$ than the main error sources discussed earlier in this appendix.

\section{REFERENCES}

Bailey, J. W., E. Hobart, H. H. Moeller, J. H. Filloux, and A. D. Chave, 2001: Low power instrumentation to measure barotropic fluctuations. Vol. 3, Proc. Oceans 2001, Honolulu, HI, IEEE, $1886-1890$.

Beal, L. M., and H. L. Bryden, 1999: The velocity and vorticity structure of the Agulhas Current at $32^{\circ} \mathrm{S}$. J. Geophys. Res., 104, $5151-5176$.

Bretherton, F. P., R. E. Davis, and C. B. Fandry, 1976: A technique for objective analysis and design of oceanographic experiments applied to MODE-73. Deep-Sea Res., 23A, 559-582.

Chaplin, G. F., and D. R. Watts, 1984: Inverted echo sounder devel- opment. IEEE Oceans '84 Conference Record, Vol. 1, IEEE, 249-253.

Chave, A. D., and D. S. Luther, 1990: Low-frequency, motionally induced electromagnetic fields in the ocean. 1. Theory. J. Geophys. Res., 95, 7185-7200.

- - , and J. T. Smith, 1994: On electric and magnetic field galvanic distortion tensor decompositions. J. Geophys. Res., 99, 46694682.

- - , D. S. Luther, and J. H. Filloux, 1992: The barotropic response to atmospheric forcing. J. Geophys. Res., 97, 9565-9593.

,---- , and,-- 1997 : Observations of the boundary current system at $26.5^{\circ} \mathrm{N}$ in the subtropical North Atlantic Ocean. $J$. Phys. Oceanogr., 27, 1827-1848.

,---- , and C. S. Meinen, 2002: Correction of motional electric field measurements for galvanic distortion. J. Atmos. Oceanic Technol., submitted.

Chiswell, S. M., 1994: Using an array of inverted echo sounders to measure dynamic height and geostrophic current in the North Pacific subtropical gyre. J. Atmos. Oceanic Technol., 11, 14201424.

- -, D. R. Watts, and M. Wimbush, 1986: Using inverted echo sounders to measure dynamic height in the eastern equatorial Pacific during the 1982-83 El Niño. Deep-Sea Res., 33A, 981991.

Cokelet, E. D., M. L. Schall, and D. M. Dougherty, 1996: ADCPreferenced geostrophic circulation in the Bering Sea basin. $J$. Phys. Oceanogr., 26, 1113-1128.

Cox, C. S., J. H. Filloux, and J. C. Larsen, 1970: Electromagnetic studies of ocean currents and electrical conductivity below the ocean-flow. The Sea, M. N. Hill, Ed., New Concepts of Sea Floor Evolution, Part I, Vol. 4, Wiley and Sons, 637-693.

Doherty, K. W., D. E. Frye, S. P. Liberatore, and J. M. Toole, 1999: A moored profiling instrument. J. Atmos. Oceanic Technol., 16, $1816-1829$.

Donohue, K. A., G. E. Hufford, and M. S. McCartney, 1999: Sources and transport of the Deep Western Boundary Current east of the Kerguelen Plateau. Geophys. Res. Lett., 26, 851-854.

- - , E. Firing, and L. Beal, 2000: Comparison of three velocity sections of the Agulhas Current and Agulhas Undercurrent. $J$. Geophys. Res., 105, 28 585-28 595.

Filloux, J. H., 1982: Magnetotelluric experiment over the ROSE area. J. Geophys. Res., 87, 8364-8378.

- - 1987: Instrumentation and experimental methods for oceanic studies. Geomagnetism, Vol. 1, J. A. Jacobs, Ed., Academic Press, 143-248.

Firing, E., S. Wijffels, and P. Hacker, 1998: Equatorial subthermocline currents across the Pacific. J. Geophys. Res., 103, 21 413-21 423.

Garzoli, S. L., and A. Bianchi, 1987: Time-space variability of the local dynamics of the Malvinas-Brazil confluence as revealed by inverted echo sounders. J. Geophys. Res., 92, 1914-1922.

- - , and A. L. Gordon, 1996: Origins and variability of the Benguela Current. J. Geophys. Res., 101, 897-906.

Gille, S. T., 1994: Mean sea surface height of the Antarctic Circumpolar Current from Geosat data: Method and application. J. Geophys. Res., 99, 18 255-18 273.

Groom, R. W., and R. C. Bailey, 1989: Decomposition of magnetotelluric impedance tensors in the presence of local three-dimensional galvanic distortion. J. Geophys. Res., 94, 1913-1925.

Hallock, Z. R., 1987: Regional characteristics for interpreting inverted echo sounder (IES) observations. J. Atmos. Oceanic Technol., 4, 298-304.

He, Y., D. R. Watts, and K. L. Tracey, 1998: Determining geostrophic velocity shear profiles with inverted echo sounders. J. Geophys. Res., 103, 5607-5622.

James, C. E., and M. Wimbush, 1995: Inferring dynamic height variations from acoustic travel time in the Pacific Ocean. J. Oceanogr., 51, 553-569.

Johns, E., D. R. Watts, and H. T. Rossby, 1989: A test of geostrophy in the Gulf Stream. J. Geophys. Res., 94, 3211-3222. 
Johns, W. E., T. J. Shay, J. M. Bane, and D. R. Watts, 1995: Gulf Stream structure, transport, and recirculation near $68^{\circ} \mathrm{W}$. J. Geophys. Res., 100, 817-838.

Larsen, J. C., 1992: Transport and heat flux of the Florida Current at $27^{\circ} \mathrm{N}$ derived from cross-stream voltages and profiling data: Theory and observations. Philos. Trans. Roy. Soc. London, A338, 169-236.

Luther, D. S., J. H. Filloux, and A. D. Chave, 1991: Low-frequency, motionally induced electromagnetic fields in the ocean. 2. Electric field and Eulerian current comparison. J. Geophys. Res., 96, $12797-12814$

- -, A. D. Chave, J. A. Church, J. H. Filloux, J. G. Richman, S. R. Rintoul, and D. R. Watts, 1997: The Sub-Antarctic Flux and Dynamics Experiment (SAFDE). WOCE Notes, No. 9, U.S. WOCE Office, College Station, TX, 8-12.

Meinen, C. S., 2001: Structure of the North Atlantic Current in stream-coordinates and the circulation in the Newfoundland Basin. Deep-Sea Res., 48A, 1553-1580.

- - , and D. R. Watts, 2000: Vertical structure and transport on a transect across the North Atlantic Current near $42^{\circ} \mathrm{N}$ : Time series and mean. J. Geophys. Res., 105, 21 869-21 891.

,---- , and R. A. Clarke, 2000: Absolutely referenced geostrophic velocity and transport on a section across the North Atlantic Current. Deep-Sea Res., 47A, 309-322.

Moore, J. K., M. R. Abbott, and J. G. Richman, 1999: Location and dynamics of the Antarctic Polar Front from satellite sea surface temperature data. J. Geophys. Res., 104, 3059-3073.

Petitt, R. A., J. H. Filloux, and A. D. Chave, 1992: Technology for the measurement of oceanic low frequency electric fields. Proc. Oceans'92, Vol. 2, Newport, RI, IEEE, 642-647.

Phillips, H. E., and S. R. Rintoul, 2000: Eddy variability and energetics from direct current measurements in the Antarctic Circumpolar Current south of Australia. J. Phys. Oceanogr., 30, 3050-3076.

Pickart, R. S., and D. R. Watts, 1990: Using the inverted echo sounder to measure vertical profiles of Gulf Stream temperature and geostrophic velocity. J. Atmos. Oceanic Technol., 7, 146-156.
- - , and S. S. Lindstrom, 1994: A comparison of techniques for referencing geostrophic velocities. J. Atmos. Oceanic Technol., 11, 814-824.

Pond, S., and G. L. Pickard, 1983: Introductory Dynamical Oceanography. 2d ed. Pergamon Press, 329 pp.

Quinn, J. M., R. J. Coleman, S. Macmillan, and D. R. Barraclough, 1997: The 1995 revision of the joint US/UK geomagnetic field models. II. Main field. J. Geomagn. Geoelectr., 49, 245-261.

Rossby, T., 1969: On monitoring depth variations of the main thermocline acoustically. J. Geophys. Res., 74, 5542-5546.

- - , J. Fontaine, and J. Hummon, 1991: Measuring mean velocities with POGO. J. Atmos. Oceanic Technol., 8, 713-717.

Sanford, T. B., 1971: Motionally-induced electric and magnetic fields in the sea. J. Geophys. Res., 76, 3476-3492.

- - 1986: Recent improvements in ocean current measurement from motional electric fields and currents. Proc. Third Working Conf. on Current Measurement, Airlie, VA, IEEE, 65-76.

Saunders, P. M., and B. A. King, 1995: Bottom currents derived from a shipborne ADCP on WOCE cruise A11 in the South Atlantic. J. Phys. Oceanogr., 25, 329-347.

Smith, W. H. F., and D. T. Sandwell, 1994: Bathymetric prediction from dense satellite altimetry and sparse shipboard bathymetry. J. Geophys. Res., 99, 21 803-21 824.

Trivers, G., and M. Wimbush, 1994: Using acoustic travel time to determine dynamic height variations in the North Atlantic Ocean. J. Atmos. Oceanic Technol., 11, 1309-1316.

Watts, D. R., and H. T. Rossby, 1977: Measuring dynamic heights with inverted echo sounders: Results from MODE. J. Phys. Oceanogr., 7, 345-358.

- - , and W. E. Johns, 1982: Gulf Stream meanders: Observations on propagation and growth. J. Geophys. Res., 87, 9467-9476.

- - , K. L. Tracey, J. M. Bane, and T. J. Shay, 1995: Gulf Stream path and thermocline structure near $74^{\circ} \mathrm{W}$ and $68^{\circ} \mathrm{W}$. J. Geophys. Res., 100, 18 291-18 312.

- - , C. Sun, and S. Rintoul, 2001: Gravest empirical modes determined from hydrographic observations in the Subantarctic Front J. Phys. Oceanogr., 31, 2186-2209. 
Copyright $@ 2002$ EBSCO Publishing 